\title{
An Approach to Numerical Identification of Bacterial Species
}

\author{
BY M. TSUKAMURA \\ The National Chubu Hospital, Obu, Aichi, Japan 474 \\ (Received 30 July 1975 ; revised 5 November 1975)
}

\begin{abstract}
SUMMARY
The distribution of matching coefficients ( $M$ values) for strains of a species to their own 'hypothetical mean organism' (HMO) or to HMO patterns of other organisms was studied in 754 strains of 19 mycobacterial species, testing for 9I discriminating characters. The M values of strains of a species to the HMO of other species usually showed a normal distribution, and $M$ values to their own HMO showed either a normal distribution or a binomial distribution, depending on the mean of $M$ values. If the number of test characters was large, the binomial distribution usually resembled the normal distribution.

After preparation of the HMO for every species and estimation of the mean of the $M$ values $(\bar{M})$ and the standard deviation (s), numerical identification could be carried out: if a test strain had an M value to the HMO of species $x$ that only fell within the range $(\bar{M} \pm 2 s)$ for species $x$, the strain would be identified as a member of that species.
\end{abstract}

\section{INTRODUCTION}

Recent aspects of numerical identification were reported by several authors (Lapage et al., I973; Bascomb et al., 1973; Willcox et al., 1973; Hill, 1974; Lapage, 1974; Sneath, 1974). Previously, Gyllenberg (I965) proposed a method of computer identification, in which he defined the 'population' in a given space by its centre of gravity and its extension (radius). Hutchinson, Johnstone \& White (1965) discussed the possibility of the separation of groups, assuming that the S-values of a group of thiobacilli gave a normal distribution curve. Tsukamura $(1967 b)$ proposed that the $t$-test could be used for comparing two taxonomic groups, assuming that matching coefficients ( $M$ values) within a cluster showed a normal distribution. He carried out numerical identification of nocardiae, comparing the characters of test strains and those of 'hypothetical mean organisms' (Tsukamura \& Mizuno, 1968; Tsukamura, 1969). The method of identification was based on the hypothesis that the $M$ values of individual members of a species to its 'hypothetical mean organism' (HMO) show a normal distribution curve. Later, Tsukamura (I97I) calculated permissible limits of $M$ values for strains of various mycobacterial species to their own HMO and to HMO patterns of other species in the group. Bergan (1972) questioned the presence of a normal distribution, but presented no evidence for either the presence or absence of such a distribution. Our aim was to show the presence of a normal distribution of $M$ values and their use in numerical identification.

\section{METHODS}

A total of 754 strains of 19 mycobacterial species was tested for 97 characters. Most of the strains were described by Tsukamura (1967a) and Tsukamura \& Mizuno (1968). Three taxa previously known as Mycobacterium scrofulaceum (sporadic isolates), $M$. borstelense and $M$. abscessus are shown here as $M$. gordonae, $M$. chelonei subsp. chelonei and 
$M$. chelonei subsp. abscessus, respectively, as recommended by the International Working Group for Mycobacterial Taxonomy (Wayne et al., 1971; Kubica et al., 1972).

The 97 characters tested were described by Tsukamura \& Mizuno (I968). Of these, three showed positive matches and three negative matches, thus, 9I characters were effective in differentiating test strains. The matching coefficients ( $M$ values) were estimated according to the following equation:

$$
\mathrm{M}(\%)=\left(n_{s} \times 100\right) /\left(n_{s}+n_{d}\right)
$$

in which $n_{d}$ is the number of characters of the test strain having different code symbols from the HMO and $n_{s}$ is the number of characters having similar code symbols.

The HMO was prepared according to the method of Tsukamura \& Mizuno (1968), and is a slight modification of the hypothetical median organism of Liston, Wiebe \& Colwell (1963).

The $\mathrm{M}$ values for each strain of a species (taxon) to the HMO of its own species and to the HMO patterns of other species were estimated, and the mean of $M$ values $(\bar{M})$ for each species and the standard deviation (s) were calculated.

Theoretical considerations. All test characters are regarded as equal. For any one character, the probability that the HMO and the test strain have different symbols $(+-)$ is $p$, and the probability that they have the same symbols is $q=(\mathrm{I}-p)$. The $n$ characters of the test strain are regarded as a set of $n$ trials, in which the probability that the HMO and test strain have $x$ symbols that are different, and $(n-x)$ that are the same is given by the following equation:

$$
P(x)=\frac{n !}{x !(n-x) !} \cdot p^{x} \cdot q^{n-x} \quad(x=\mathrm{I}, 2,3, \ldots, n)
$$

The distribution defined by a sequence of the above probabilities is known as a binomial distribution (Davies, 1949; Kondo, 1944; Okamatsu, 1953; Bennett \& Franklin, 1956). The shape of the binomial distribution curve is influenced by the values of $p$ and $n$ (Kondo, I944; Okamatsu, 1953). If $n \times p$ is greater than 5, the curve resembles the normal distribution curve. In this study, $n$ is $9 \mathrm{I}$, so if $p$ is greater than $0.06(\bar{M}$ less than $94 \%$ ), a curve resembling the normal distribution curve should be obtained.

\section{RESULTS AND DISCUSSION}

Distribution of $M$ values for the strains of each species to their own HMO and to HMO patterns of other species

In most cases, the class value had to be modified before drawing the distribution curve. For example, the distribution of $\mathrm{M}$ values of 77 strains of $M$. fortuitum subsp. fortuitum appeared to be irregular (Fig. I $a$ ); but by changing the class value to $2 \%$ so that, for example, the strains with $\mathrm{M}$ values of $99 \%$ and $100 \%$ were plotted at class $100 \%$, the curve became a typical normal distribution curve (Fig. I $b$ ).

In only one case was the shape of the distribution curve questionable: the curve for $M$. intracellulare (76 strains) was bimodal (Fig. $2 a$ ). In an attempt to analyse the origin of the bimodal curve, the strains were divided into two groups: A, consisting of 33 strains with $\mathrm{M}$ values to the HMO of more than $94 \%$; and B, consisting of 43 strains with $\mathrm{M}$ values of less than $93 \%$. New HMO patterns $\left(\mathrm{HMO}_{\mathbf{A}}\right.$ and $\mathrm{HMO}_{\mathrm{B}}$ ) were prepared for both groups, and the distribution of $M$ values of both groups to each new HMO was plotted. The distribution curves showed considerable overlap (Fig. $2 b, c$ ), and the two groups were considered as not separable. The bimodal curve may arise from variability of characters in strains. 


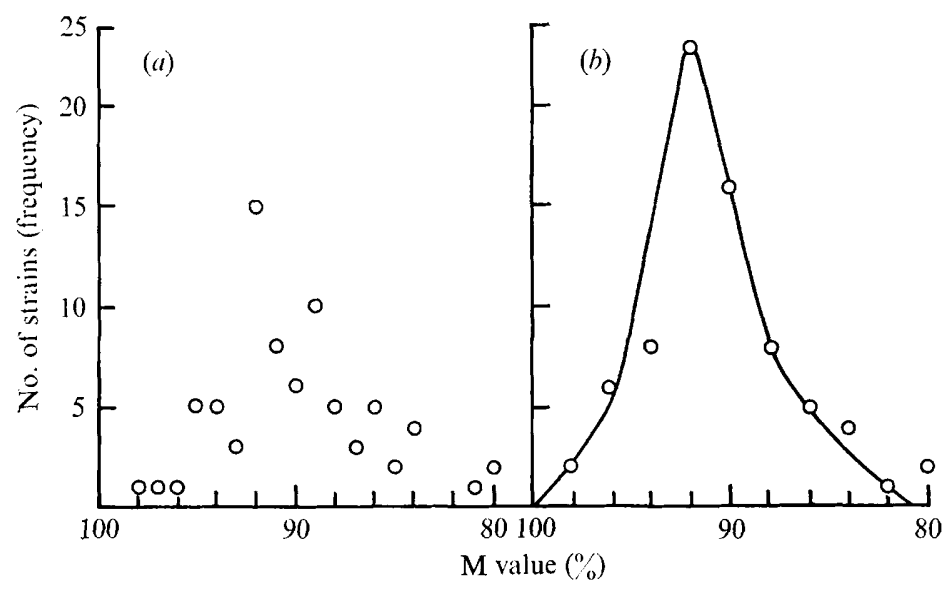

Fig. I. Distribution of $M$ values of 77 strains of $M$. fortuitum subsp. fortuitum to their own HMO, plotted at $(a) 1 \%$ intervals, and $(b) 2 \%$ intervals.

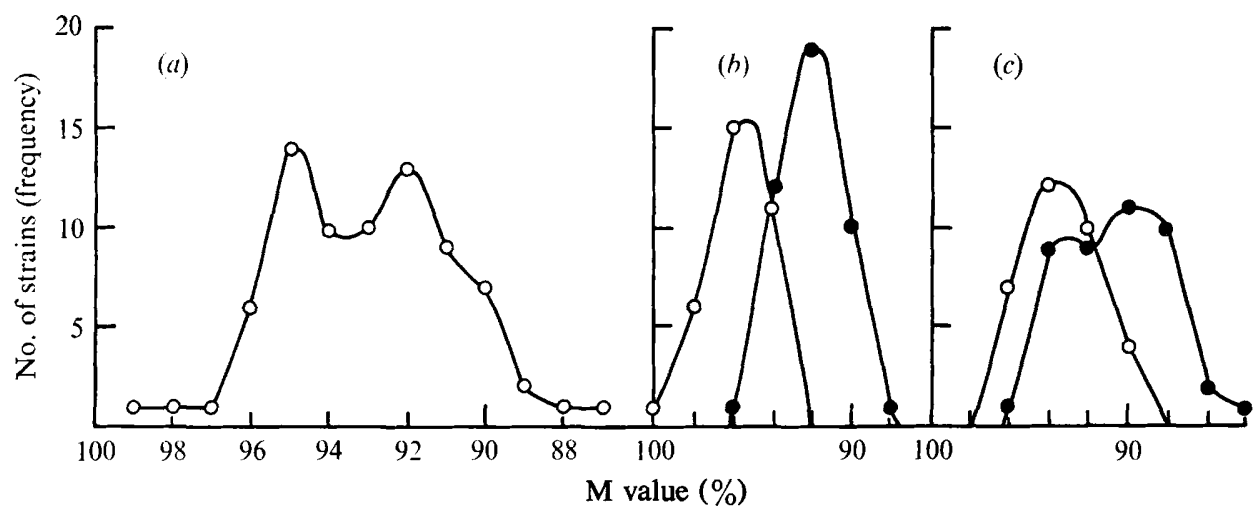

Fig. 2. Distribution of $M$ values of strains of $M$. intracellulare to their own HMO. The strains were divided into two groups: $A$, consisting of 33 strains with $M$ values to original $H M O$ of more than $94 \%$; and $B$, consisting of 43 strains with $M$ values of less than $93 \%$. (a) Distribution of $M$ values for all 76 strains to the HMO prepared from all strains. (b) Distribution of $\mathrm{M}$ values to the $\mathrm{HMO}_{\mathrm{A}}$ for group $A(O)$ and group B (O). (c) Distribution of $\mathbf{M}$ values to the $\mathrm{HMO}_{\mathrm{B}}$ for group $\mathrm{A}(\mathrm{O})$ and group B (O).

\section{Relationship between species}

Relationships between species were examined in two ways: (i) by comparing the distributions of $M$ values of the strains of one species to their own HMO and to HMO patterns of other species; or (ii) by comparing the distribution of $M$ values of the strains of different species to the HMO of one species.

In both (i) and (ii), the relationships between the species were classified according to three criteria: if the range $(\bar{M} \pm 2 s)$ of two taxa did not overlap, they were classed as clearly separable; if the range $(\overline{\mathrm{M}} \pm 2 \mathrm{~s})$ of two taxa overlapped, but the two means differed significantly $(P$ less than $5 \%$ ), they were classed as partially separable; if the two means did not differ significantly ( $P$ more than $5 \%$ ), they were classed as not separable. The $t$-test may be applied to the comparison, as the distribution can practically be considered as normal.

Examples of the distribution of $M$ values of the strains of a species to various HMO patterns, and of the strains of various species to the HMO of one species, are shown in Figs 3, 4 and 5. The M values to HMO patterns of other species always formed a normal 


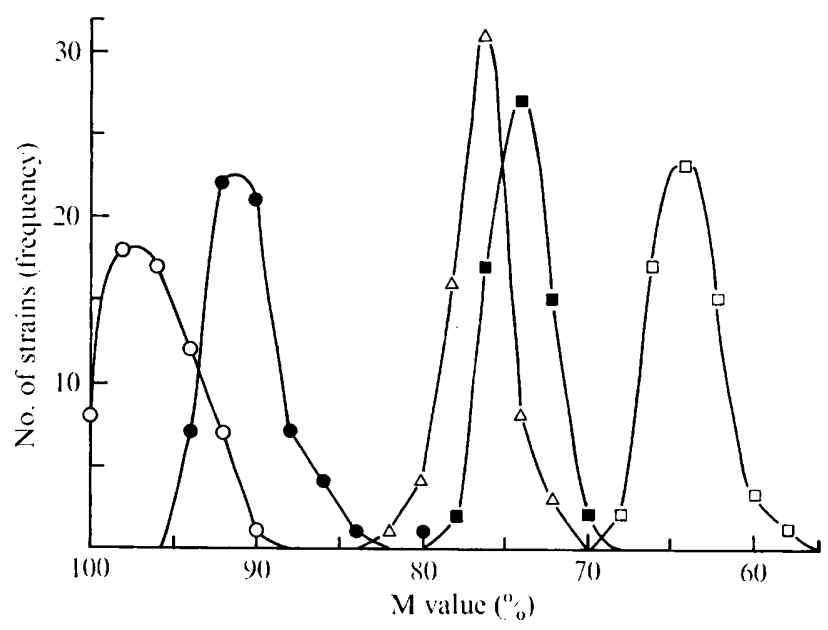

Fig. 3. Distribution of $\mathrm{M}$ values of 63 strains of $M$. fortuitum subsp. thermophilum to HMO patterns of: $\bigcirc, M$. fortuitum subsp. thermophilum;,$M$. fortuitum subsp. fortuitum; $\triangle, M$. aurum; $\square$ M. smegmatis subsp. smegmatis; $\mathbf{0}$, M. phlei.

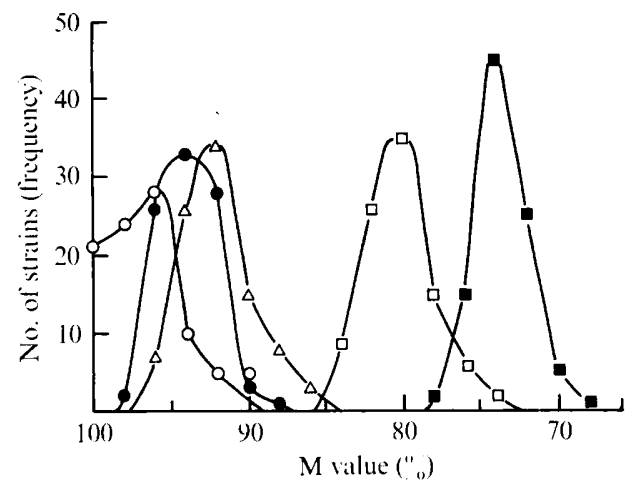

Fig. 4

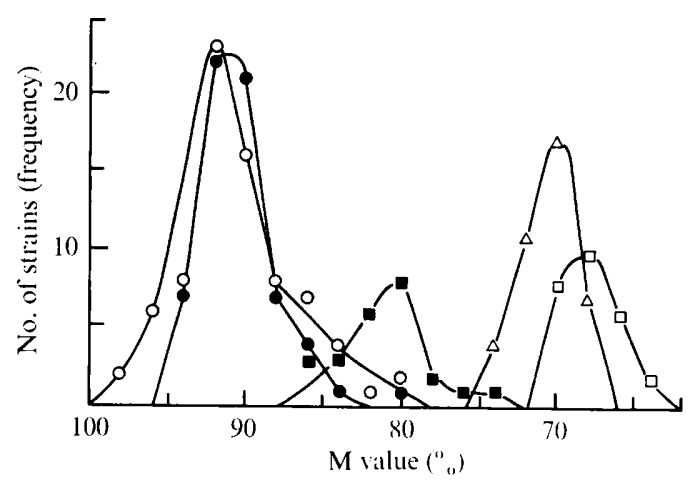

Fig. 5

Fig. 4. Distribution of $\mathrm{M}$ values of 93 strains of $M$. nonchromogenicum to HMO patterns of: $\bigcirc, M$. nonchromogenicum;,$M$. avium; $\triangle, M$. intracellulare; $\square, M$. chitae; $\square, M$. chelonei subsp. chelonei.

Fig. 5. Distribution of $\mathrm{M}$ values of strains of various rapidly growing mycobacterial species to the HMO of $M$. fortuitum subsp. fortuitum. $\bigcirc, M$. fortuitum subsp. fortuitum (77 strains);,$M$. fortuitum subsp. thermophilum (63 strains); $\triangle, M$. thermoresistible (39 strains); $\square, M$. smegmatis subsp. smegmatis (26 strains); $\square$, M. chelonei subsp. abscessus (24 strains).

distribution, but the M values to their own HMO sometimes showed a binomial distribution, e.g. $M$. nonchromogenicum (Fig. 4), or an intermediate between the normal and binomial distribution, e.g. M. fortuitum subsp. thermophilum (Fig. 3).

As discussed previously, if $p$ is larger than 0.06 ( $\overline{\mathrm{M}}$ less than $94 \%$ ), the distribution curve is expected to be of the normal shape, as we have found. The mean M values for strains of $M$. fortuitum subsp. thermophilum and of $M$. nonchromogenicum to their own HMO patterns were $95.6 \%$ and $96.2 \%$ respectively, and $p$ was about 0.04 in both cases. The shapes of the distribution curves were of the binomial distribution type (Figs 3 and 4). On the other hand, the mean $\mathrm{M}$ value for strains of $M$. fortuitum subsp. fortuitum to their own HMO was 
Table I. Mean $(\overline{\mathrm{M}})$ and standard deviation $(s)$ of $M$ values for the members of various species to the HMO patterns

The number in parentheses shows the percentage of strains that fell within the range $(\overline{\mathrm{M}} \pm 2 s)$ estimated in each case from a histogram of $\mathbf{M}$ values; and $n$ is the number of strains used.

\begin{tabular}{|c|c|c|c|c|}
\hline \multirow[b]{2}{*}{ Species } & \multicolumn{4}{|c|}{ HMO } \\
\hline & $\begin{array}{l}\text { M. tuberculosis* } \\
n=90\end{array}$ & $\begin{array}{l}\text { M. kansasii } \\
n=12\end{array}$ & $\begin{array}{c}\text { M. scrofulaceum } \\
n=26\end{array}$ & $\begin{array}{l}\text { M. nonchromo- } \\
\text { genicum } \\
n=93\end{array}$ \\
\hline M. bovis & $95 \cdot 6 \pm I \cdot 4(100)$ & $81 \cdot 5 \pm 2 \cdot 9(100)$ & $73 \cdot 5 \pm 2 \cdot 7(96)$ & $76 \cdot 9 \pm 2 \cdot 6(94)$ \\
\hline M. tuberculosis* & $98 \cdot 0 \pm \mathrm{I} \cdot 2(93)$ & $82.6 \pm 2.9(100)$ & $72 \cdot 5 \pm 2 \cdot 7(96)$ & $76 \cdot 3 \pm 2 \cdot 2(94)$ \\
\hline M. tuberculosis $\dagger$ & $97 \cdot 6 \pm 1 \cdot 0(99)$ & $85 \cdot 9 \pm 2 \cdot 7(92)$ & $72 \cdot 4 \pm 2 \cdot 6(96)$ & $75 \cdot 3 \pm 2 \cdot 2(94)$ \\
\hline M. kansasii & $83 \cdot 8 \pm 1 \cdot 2(90)$ & $97 \cdot 0 \pm 2 \cdot I(100)$ & $82 \cdot 3 \pm 2 \cdot 8(96)$ & $8 I \cdot 5 \pm I \cdot 7(97)$ \\
\hline M. marinum & $70.8 \pm 0.9(97)$ & $84 \cdot 5 \pm 2 \cdot 5(92)$ & $83 \cdot 4 \pm 2 \cdot 2(96)$ & $8 I \cdot 7 \pm 3 \cdot I(95)$ \\
\hline M. scrofulaceum $\ddagger$ & $7 I \cdot 4 \pm I \cdot 3(97)$ & $82 \cdot 9 \pm I \cdot 7(92)$ & $95 \cdot 4 \pm 2 \cdot I(100)$ & $93 \cdot I \pm 2 \cdot 2(96)$ \\
\hline M. scrofulaceum\$ & $73.4 \pm 3 \cdot 9(100)$ & $85 \cdot I \pm I \cdot 6(92)$ & $94 \cdot 5 \pm 2 \cdot 0(96)$ & $92 \cdot 6 \pm 2 \cdot 3(94)$ \\
\hline M. gordonae & $69 \cdot 9 \pm 1 \cdot 2(100)$ & $8 \mathrm{I} \cdot \mathrm{I} \pm 2 \cdot 5(100)$ & $99 \cdot 0 \pm 2 \cdot 3(96)$ & $90.5 \pm 2 \cdot 7(94)$ \\
\hline M. avium & $74 \cdot 4 \pm I \cdot 3(97)$ & $80.2 \pm 0.8(92)$ & $9 I \cdot 4 \pm I \cdot 8(92)$ & $93 \cdot 5 \pm 1 \cdot 9(98)$ \\
\hline$M$. intracellulare & $73.5 \pm 0.8(100)$ & $85 \cdot 2 \pm 1 \cdot 6(100)$ & $92 \cdot 4 \pm 2 \cdot 5(100)$ & $91 \cdot 7 \pm 2 \cdot 3(94)$ \\
\hline M. nonchromogenicum & $74 \cdot 4 \pm 1 \cdot 3(97)$ & $83 \cdot 3 \pm I \cdot 2(92)$ & $92 \cdot 4 \pm 1 \cdot 5(100)$ & $96 \cdot 2 \pm 2 \cdot 7(95)$ \\
\hline M. novum & $87 \cdot 3 \pm 1 \cdot 2(100)$ & $83 \cdot 2 \pm 2 \cdot 9(92)$ & $83 \cdot 2 \pm 2 \cdot 8(100)$ & $88 \cdot 2 \pm 2 \cdot 3(95)$ \\
\hline M. gastri & $76 \cdot 1 \pm I \cdot 0(94)$ & $87 \cdot 8 \pm 2 \cdot 0(100)$ & $89 \cdot 6 \pm 2 \cdot 9(96)$ & $9 \mathrm{I} \cdot 2 \pm 2 \cdot 6(98)$ \\
\hline M. thermoresis & $65 \cdot 1 \pm I \cdot 2(97)$ & $75 \cdot 2 \pm 1 \cdot 6(100)$ & $79 \cdot 9 \pm 2 \cdot 4(96)$ & $78 \cdot 2 \pm 1 \cdot 9(95)$ \\
\hline M. chitae & $62 \cdot 5 \pm I \cdot 3(97)$ & $76 \cdot 0 \pm 2 \cdot 5(92)$ & $8 I \cdot 2 \pm 2 \cdot 8(96)$ & $79 \cdot 8 \pm 2 \cdot 2(95)$ \\
\hline M. chelonei & $65 \cdot 9 \pm 1 \cdot 2(100)$ & $74 \cdot 2 \pm I \cdot 8(92)$ & $74 \cdot 5 \pm 2 \cdot 2(93)$ & $73 \cdot 0 \pm I \cdot 8(94)$ \\
\hline
\end{tabular}

* Fresh isolates; $\dagger$ laboratory strains; $\ddagger$ human isolates; $\S$ soi 1 isolates; $\uparrow$ subspecies chelonei.

$90.0 \%(p=0 \cdot 1)$ and the shape of the distribution curve was of the normal distribution type. Thus the relationship between the $p$ value and the shape of the distribution curve was as expected from theoretical considerations. The mean $\mathbf{M}$ values for the strains of a species to HMO patterns of other species were usually less than $94 \%$, and, as expected, they showed a normal distribution.

If a distribution curve indicates a normal distribution of $M$ values, then $95 \%$ of those $M$ values should fall within the range $(\bar{M} \pm 2 s)$. This has been demonstrated, and some examples are shown in Table I. Even in cases where the distribution curves indicate a binomial distribution, about $95 \%$ of the strains of the species fell within the range. The results suggest that, in practice, all curves can be treated as normal distribution curves. This finding provides a simple method of identification.

\section{A simple method of numerical identification}

Numerical classification is made using a large number (50 to roo, if possible about roo) of effective characters, and each cluster is named. The HMO for each species is prepared, and $M$ values to the HMO are estimated. The mean, $\bar{M}$, and the standard deviation, $s$. are calculated. If an unknown strain shows an $\mathrm{M}$ value to the HMO of species $x$, which falls within the range ( $\overline{\mathrm{M}} \pm 2 \mathrm{~s})$ of the species $x$, and $\mathrm{M}$ values to the HMO patterns of other species are outside the ranges $(\bar{M} \pm 2 s)$, the test strain is identified as a member of species $x$. This method of numerical identification was used by Tsukamura (I969) for identification of nocardiae, though the basis of the method was not shown at that time. 


\section{REFERENCES}

Bascomb, S., LAPage, S. P., Curtis, M. A. \& Willcox, W. R. (1973). Identification of bacteria by computer: identification of reference strains. Journal of General Microbiology 77, 29 I-3 I 5.

Bennett, C. A. \& Franklin, N. L. (I956). Statistical Analysis in Chemistry and the Chemical Industry. London: Chapman \& Hall (authorized translation into Japanese, Tokyo: Maruzen).

Bergan, T. (1972). Survey of numerical techniques for grouping. Bacteriological Reviews 35, 379-389.

Davies, O. L. (1949). Statistical Methods in Research ad Production, 2nd edn. London: Oliver \& Boyd.

GyllenBERG, H. G. (1965). A model for computer identification of micro-organisms. Journal of General Microbiology 39, 40I-405.

HILL, L. R. (1974). Theoretical aspects of numerical identification. International Journal of Systematic Bacteriology 24. 494-499.

Hutchinson, M., Johnstone, K. I. \& White, D. (1965). The taxonomy of certain thiobacilli. Journal of General Microbiology 4r, 357-366.

Kondo, T. (1944). Statistics. Tokyo: Iwanami Co.

Kubica, G. P., Baess, I., Gordon, R. E., Jenkins, P. A., Kwapinski, J. B. G., McDurmont, C., Pattyn, S. R., Sarto, H., Silcox, V. A., Stanford, J. L., Takeya, K. \& Tsukamura, M. (1972). A co-operative numerical analysis of rapidly growing mycobacteria. Journal of General Microbiology 73, 55-70.

LAPAGE, S. P. (1974). Practical aspects of probabilistic identification of bacteria. International Journal of Systematic Bacteriology 24, 500-507.

Lapage, S. P., Bascomb, S., Willcox, W. R. \& CuRTis, M. A. (I973). Identification of bacteria by computer: general aspects and perspectives. Journal of General Microbiology 77, 273-290.

Liston, J., WiEbe, W. \& ColWell, R. R. (I963). Quantitative approach to the study of bacterial species. Journal of Bacteriology 85, 106I-1070.

OKamatsu, M. (1953). A Note on Statistics. Tokyo: Ohm Co.

SNEATH, P. H. A. (1974). Test reproducibility in relation to identification. International Journal of Systematic Bacteriology 24, 508-523.

Tsukamura, M. (1967a). Identification of mycobacteria. Tubercle 48, 3 I I-338.

TSUKAMURA, M. (1967 b). A statistical approach to the definition of bacterial species. Japanese Journal of Microbiology II, 213-220.

TSUKAmURA, M. (1969). Numerical taxonomy of the genus Nocardia. Journal of General Microbiology 56, 265287.

TSUKAMURA, M. (197I). Some considerations on classification of mycobacteria. Definition of bacterial species by introduction of the concept of 'hypothetical median or mean organism'. Japanese Journal of Tuberculosis and Chest Diseases $17,18-30$.

Tsukamura, M. \& Mizuno, S. (1968). 'Hypothetical mean organisms' of mycobacteria. A study of classification of mycobacteria. Japanese Journal of Microbiology 12, 371-384.

Wayne, L. G., Dietz, T. M., Gernez-RieuX, C., Jenkins, P. A., KäPPler, W., Kubica, G. P., KwaPinski, J. B. G., Meissner, G., Pattyn, S. R., Runyon, E. H., Schröder, K. H., Silcox, V. A., Tacquet, A., Tsukamura, M. \& Wolinsky, E. (1971). A co-operative numerical analysis of scotochromogenic slowly growing mycobacteria. Journal of General Microbiology 66, 255-27I.

Willcox, W. R., LAPAge, S. P., Bascomb, S. \& CuRTis, M. A. (I973). Identification of bacteria by computer: theory and programming. Journal of General Microbiology 77, 31 7-330. 